\title{
SEISMIC DESIGN OF BRIDGES
}

\section{SECTION 10}

DYNAMIC ANALYSIS

\section{J.H. Wood*, R.W.G. Blakeley*, M.J.N. Priestley**}

\subsection{NOTATION}

$$
\begin{aligned}
& \text { C = damping matrix } \\
& \mathrm{k}_{1}, \mathrm{k}_{2}=\text { elastic and post yield stiffnesses } \\
& \text { respectively of the idealized } \\
& \text { moment-curvature relationships } \\
& \underline{\mathrm{K}}=\text { stiffness matrix } \\
& \mathrm{M} \quad=\text { bending moment } \\
& \mathrm{M}_{\mathrm{Cr}}=\text { moment at first cracking of } \\
& \text { concrete } \\
& M_{1 i}=\text { moment depth of non degrading } \\
& \text { hysteresis loop for prestressed } \\
& \text { concrete } \\
& \mathrm{M}_{\mathrm{u}} \quad=\text { theoretical ultimate moment } \\
& \text { based on ideal strength } \\
& =\text { mass matrix } \\
& =\text { Rayleigh damping scalar factor } \\
& \text { for mass } \\
& =\text { Rayleigh damping scalar factor } \\
& \text { for stiffness } \\
& \text { = equivalent viscous damping ratio } \\
& \text { = overall structural displacement } \\
& \text { ductility factor } \\
& =\text { section curvature } \\
& \phi_{\mathrm{Cr}}=\text { curvature at first cracking of } \\
& \text { concrete } \\
& \phi_{Y}=\text { section curvature when tension } \\
& \text { reinforcement reaches full yield }
\end{aligned}
$$

* Ministry of Works and Development, Wellington.

** Reader in Civil Engineering, University of Canterbury, Christchurch.

\subsection{BRIDGES REQUIRING DYNAMIC ANALYSIS}

Dynamic analysis to obtain maximum earthquake forces and displacements or ductility demand should be carried out for bridges that fall in one or more of the following categories;

(a) Major bridge structures considered to be of particular importance.

(b) Mass of any pier, including any allowance for hydrodynamic effects, greater than $20 \%$ of the mass of the superstructure estimated to contribute to the inertia loading on the pier.

(c) Bridges with superstructure joints that are designed to allow significant relative movement between the separated spans.

(d) Structures in which the lateral load resistance is provided by structural systems other than conventional piers and abutment structures.

(e) Suspension, cable stayed or arch bridges.

\subsection{METHODS OF ANALYSIS}

\subsubsection{Elastic Behaviour}

If the lateral load resisting elements remain essentially elastic under the design earthquake loads then the elastic modal spectral analysis method should be used. Modal responses should be computed using the design elastic response spectrum given in section 2, and the total maximum responses should be computed using the square root of the sum of the squares (SRSS) method.

\subsubsection{Moderate Inelastic Behaviour}

If the overall structural displacement ductility factor $\mu$ is less than 2 under the design earthquake, the elastic response spectrum method, as detailed in 10.2.1, should be used by adopting equivalent overall stiffnesses and viscous damping values.

\subsubsection{Inelastic Behaviour}

Where the overall structural displacement ductility factor exceeds 2, the inelastic time-history method in which the response is computed using numerical integration, should be used.

\subsection{LOADING DIRECTIONS}

Dynamic analyses should be undertaken for the two principal horizontal directions. An analysis in the vertical direction 
should also be carried out on bridges that have prestressed concrete superstructures likely to be damaged by upward forces. In both the analyses and design, the effects of concurrently loading in more than one direction may be neglected.

\subsection{INPUT GROUND MOTIONS}

The input ground motions used for time-history analyses should satisfy the following criteria;

(a)

The records should contain at least 15 seconds of strong ground shaking or have a strong shaking duration of 5 times the fundamental period of the structure, whichever is greater.

(b) The ordinates of the input ground motion spectra should not be less than $90 \%$ of the design spectrum over the range of the first three periods of vibration of the structure in the direction being considered.

The bridge should be analysed using two different input motions for each direction and the maximum computed responses from the two inputs should be adopted for design. The input motions may be assumed to be in phase at the base of all supports.

\subsection{FOUNDATION INTERACTION}

The influence of the soil foundation on the response should be taken into account using the recommendations given in section 4 .

\subsection{MATERIAL PROPERTIES}

\subsubsection{Elastic Stiffness}

Effective cracked section properties should be used in concrete members where forces arising from the design earthquake loading exceed computed cracking capacities.

\subsubsection{Inelastic Moment Curvature Idealizations}

The moment curvature relationships recommended for use in plastic hinge regions of reinforced concrete, steel and prestressed concrete members are shown in Figs 10.1 and 10.2. The idealization recommended for reinforced concrete and steel members is a bilinear non-degrading hysteresis loop with a $3 \circ$ strain hardening ratio. The recommended relationship for prestressed concrete has been taken from Blakeley and Park10.1,10.2 and the nondegrading loop shown is only applicable before the onset of concrete crushing. Further details including post crushing loops are given in references 10.1 and 10.2 .

\subsubsection{Damping}

The overall damping in the bridge system expressed as percent of critical equivalent viscous damping should generally be taken as $5 \%$. This value includes both the structural damping and the damping arising from radiation and inelastic behaviour in the foundation. For special structures such as long span steel cable supported bridges that remain elastic under earthquake loading, a lower value of damping may be appropriate. Recommendations for these bridges are given in Section 11.

If the program allows individual modal damping ratios to be input then a constant value should be used for all modes. If the program assumes Rayleigh type damping, then the values of the coefficients $\alpha$ and $\beta$ should be determined assuming the two most dominant modes of vibration in the initial elastic system to have the damping values given above.

\subsection{DESIGN FORCES AND DEFORMATIONS}

\subsection{Modal Spectral Analysis}

The design forces and deformations obtained from a modal spectral analysis should be compared with the values obtained from the simplified code analysis method. It is unlikely that the two methods will give results that differ significantly but where differences exceed $20 \%$ the reason for the variation should be investigated.

\subsubsection{Time-History Analysis}

The overall ductility demands computed by a time-history analysis should not be greater than the available structural displacement ductility factors. As specified in Section 2.1.2, the overall structural displacement ductility factor should not exceed six and individual member displacement ductilities should not exceed eight unless the requirements for additional ductility given in section 5.2 are satisfied.

\section{REFERENCES :}

10.1 Blakeley, R.W.G., \& Park, R., (1973)

"Prestressed Concrete Sections with Cyclic Flexure" Journal of the Structural Division, ASCE, Vol 99, No ST8, August 1973.

10.2 Park, R., and Blakeley, R.W.G., (1973) "The Response of Prestressed Concrete Structures to Earthquake Motions", New Zealand Engineering Vol 28 , No 2, February 1973.

\section{COMMENTARY :}

\section{General Comment -}

Techniques are available to compute the earthquake response of any bridge structure and foundation soil model. Recent refinements in numerical methods and developments in structural mechanics enable, at least in theory, an almost exact representation of the bridge and foundation.C10.5, C10.6. The main limitations to obtaining an exact solution are: 


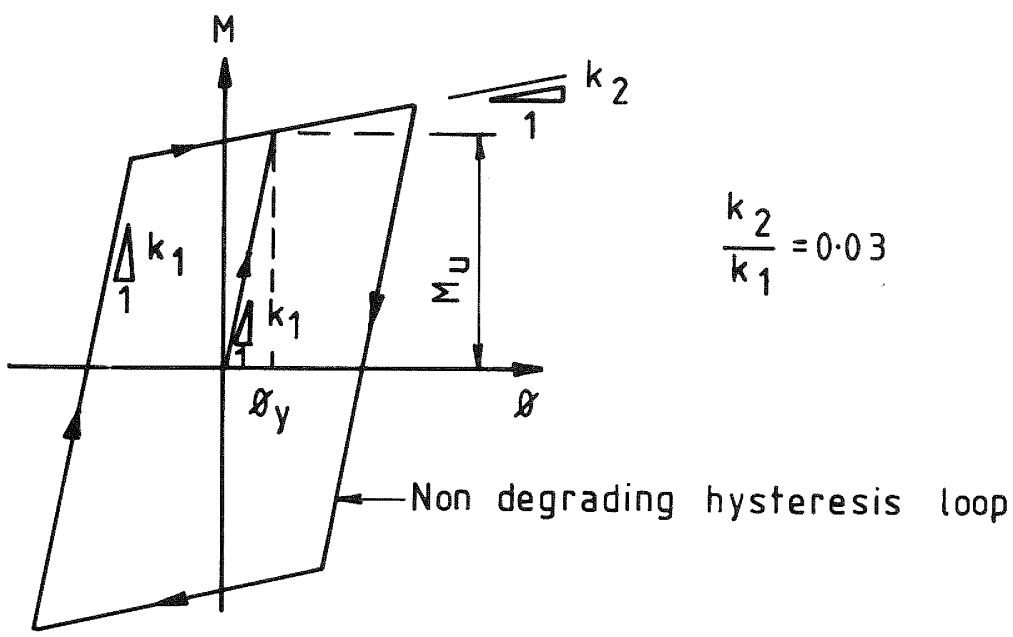

FIG. 10.1 MOMENT - CURVATURE IDEALIZATION FOR PLASTIC HINGE REGIONS IN REINFORCED CONCRETE AND STEEL MEMBERS

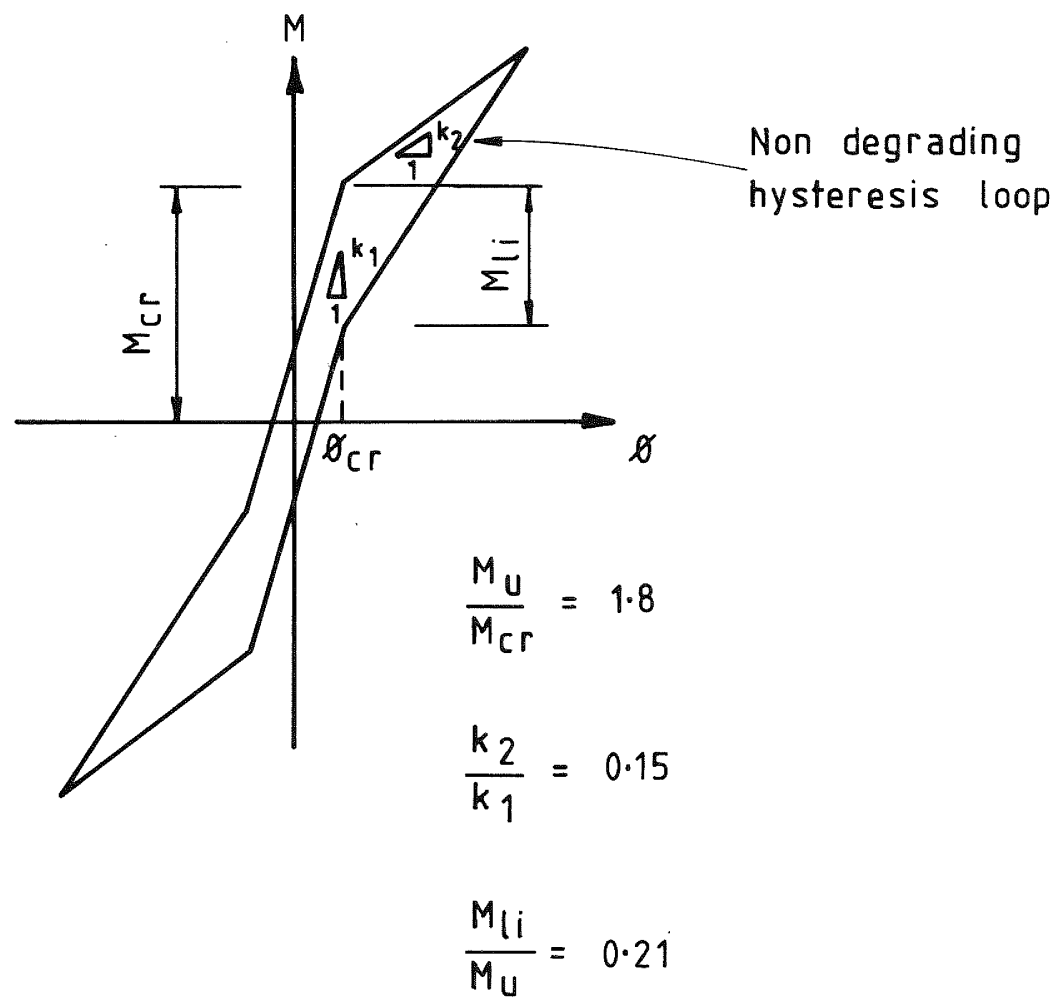

FIG. 10.2 MOMENT-CURVATURE IDEALIZATION FOR PLASTIC HINGE REGIONS IN PRESTRESSED CONCRETE 
(a) Available design time and resources.

(b) The accuracy to which most of the basic input parameters can be defined.

Difficulty in specifying sufficiently exact input parameters may arise in the following areas:

(a) Detailed character and magnitude of the earthquake ground motion.

(b) The difficulties in carrying out sufficiently detailed, site investigation so as to define the features of the local geology that affect the response of the structure.

(c) The inability to confidently determine soil dynamic properties.

(d) Limitations in the knowledge of the inelastic behaviour of concrete members subjected to multidirectional forces.

Assuming the resources were available, it would be possible to carry out the necessary investigation and testing to define the input parameters mentioned in areas (b) to (d) to an adequate degree of precision for a reasonably exact representation of a bridge and its foundation system. However, it is unlikely to be economic to obtain detailed data in most of these areas, and this combined with the uncertainty in the exact character of ground motion on saturated ralatively soft alluvium common at bridge sites, or on the underlying bed rock, severely restricts the accuracy that can at present be achieved. Thus in many practical situations the precision provided by the computer analytical method will greatly exceed the exactness to which the input parameters can be defined.

Many bridge structures have most of their mass concentrated at a single level and thus higher mode influences on the dynamic response is generally of lesser importance in bridges than buildings. Generally bridge lateral load resisting systems will have only a limited number of well defined areas in which inelastic action or plastic hinging is likely to occur and this is a further factor that generally enables bridges to be more exactly represented than buildings by the simplified code approach. However, factors such as large lateral dimensions, expansion joints, permanent ground movements and soil-structure interaction may add considerable complexity to the dynamic behaviour of some bridges. These factors are difficult to represent exactly in a sophisticated analysis and thus overall it is unlikely that dynamic analyses will lead to a significant reduction in construction cost or improvement to the design. Dynamic analyses can however provide benefits in some cases by giving a better insight into the actual behaviour during earthquakes (e.g. number of cycles of severe deformation) and also by allowing a wide range of poorly defined inputs to be examined.

At the present time it appears that for a given design effort, greater benefits can be achieved by devoting attention to refinements in both structural form and the detailing in the structural members resisting the earthquake forces, rather than by attempting to refine the analysis. Thus it is recommended that dynamic analysis should not be used for the majority of bridge structures where the dynamic behaviour can often be readily predicted by simple analysis. Methods of analysis involving greater complexity than the code approach should be used only for large and important structures and where some feature of the design is likely to add significant complexity to the dynamic response.

C10.1

Major bridge structures of particular importance would generally include bridges located on major traffic routes of unusual height or in excess of $200 \mathrm{~m}$ long, and having a high capital cost.

Where the mass of the pier is a significant proportion of the total mass contributing to inertia loading, as may be the case for very tall piers, lateral response of the piers as vertical beams with distributed mass may cause an increase in ductility demand at intended plastic hinges, an increase in seismic shear forces, or may cause plastic hinges to form at locations (eg mid-height) other than those intended by the designer. Such behaviour cannot be readily predicted by using an equivalent static lateral force and a dynamic analysis may be necessary. Hydrodynamic effects should be considered for piers in deep water, as discussed in Section 11.3.7. Articulation of the superstructure by expansion joints or hinges can result in deformation modes that are difficult to calculate using simple methods. The forces acting at the joints may include friction, impact and inelastic extension of seismic linkages. Dynamic analyses may be necessary to obtain a realistic estimate of relative displacements. Unusual structures, including suspension, cable stayed or arch bridges do not conform to the simple single-degreeof-freedom model implicit in code equivalent lateral loading. This aspect together with the generally high capital cost of such structures will generally make a dynamic analysis advisable.

C10.2.1 If the lateral load resisting system is expected to remain elastic under the design earthquake then it is recommended that the elastic modal spectral analysis method of dynamic analysis be used in preference to time-history numerical integration or other methods. The modal spectral analysis method requires significantly less computer time that other methods and can be carried out by hand if necessary. In the elastic modal spectral analysis method an elastic system is assumed for calculating the natural frequencies and mode shapes and the maximum response of each mode to the design earth- 
quake is obtained from the code elastic response spectrum. Because of the simplifying assumptions, the time at which each modal maximum response occurs is not known and an approximate method of combining the modal maxima, such as the square root of the sum of the squares method (SRSS), has to be used. Sufficiently accurate solutions can usually be obtained from the first two or three modes in each direction.

The difficulty inherent in the modal spectral approach of deciding how the individual modal maximum responses should be combined can be overcome by carrying out an elastic time-history analysis C10.21. The disadvantage of this approach is that computation costs are high and generally the improvement in precision is small. For this reason it is recommended that the modal spectral method be used where the structure remains essentially elastic.

C10.2.2 The elastic modal spectral method can be extended to analyse systems that respond with moderate amounts of inelastic behaviour (ductility factors 2 or less) C10.7, C10.8 by assuming an equivalent system. A simple approach is to use the resonant amplitude matching (RAM) method described by Jennings C10.8. The equivalent linear system has the same mass as the yielding structure and a period corresponding to the structure's yield period. The equivalent critical damping coefficient is given by:

$\zeta=\frac{2}{\mu \pi}\left(1-\frac{1}{\mu}\right) \quad\left(1-\frac{k_{2}}{k_{1}}\right)+0.05$

where $\mu=$ overall structural displacement ductility factor

$\begin{aligned} \mathrm{k}_{1}, \mathrm{k}_{2}= & \text { elastic and post yield stiffnesses } \\ & \text { respectively of the idealized } \\ & \text { bilinear system. }\end{aligned}$

The above expression is plotted in Fig. C.10.1.

C10.2.3 If a bridge is expected to have significant inelastic response and is not capable of close approximation by a single-degree-of-freedom system then the inelastic time-history method is likely to be the most satisfactory approach. Although a modal inelastic response spectrum method can be used to give an approximation to the earthquake response, $\mathrm{C} 10.1$ the main difficulty with this method is that inelastic systems do not have classical normal modes, and even where a modal representation may be an acceptable approximation it is possible that the inelastic behaviour will be important in some modes and have little influence on others. A simple example illustrating this point arises when the yielding member of a multispan bridge is located at the abutment and significant forces are produced by a beam type vibration mode of a relatively tall massive pier.

C10.3 Ideally a dynamic analysis should be performed on a three dimensional structural model with three orthogonal earthquake input components. Bearing in mind the high computational costs involved with this type of analysis it is recommended that a satisfactory approach is to consider the three principal directions, two horizontal and one vertical, to be acting independently.

At some distance from an earthquake source the amplitude of ground shaking will be strongly dependent on orientation with respect to the source; C10.15 thus assuming that the design earthquake represents the maximum amplitudes in any direction and also allowing for the probability of peak components of response occurring at the same time, the combined total stresses will not grossly exceed the maxima from the individual components.

The lowest vertical modes of vibration of many bridges have periods that lie close to the peak of typical earthquake response spectra and field measurements have indicated low damping values associated with these modes. Thus quite high vertical accelerations may result and should be taken into account in the design of prestressed concrete superstructures that could fail in a non-ductile manner when subject to uplift forces.

C10.4 Input ground motion accelerograms used for dynamic analysis need to be consistent with the design spectrum over the frequency range of the modes of vibration contributing significantly to the response. Suitable ground motions can be obtained by scaling recorded motions or by generating consistent artificial accelerograms. Computer programmes are available for generating accelerograms that have predescribed spectrac10.10,C10.12,C10.17,C10.19 and suitable records consistent with the design spectra given in Section 2 are being prepared.

Most bridges have span lengths of the same order as the wave lengths of the higher frequency waves that are associated with the high accelerations peaks in the ground motion. Thus it is clear that there will be large phase differences between the acceleration peaks at the various supports and this factor is likely to result in a significant reduction of the vibrational response that would be obtained by assuming all supports move in phase Cl0.23 The peak displacement in the recorded ground motions are generally associated with relatively long wave lengths and so significant out of phase displacements are only likely to need consideration for bridges longer than $200 \mathrm{~m}$. Out of phase movements resulting from elastic wave propogation in the soil could result in relative displacements of the order of lomm. In addition, permanent ground movements could result in even larger relative displacements and thus it would appear desirable to design longer bridges for a total out of phase movement of about $20 \mathrm{~mm}$. In soft soils it would be prudent to consider the effects of movements greater than this value.

A number of research projects are currently being conducted to study the influence of out of phase inputs on the 


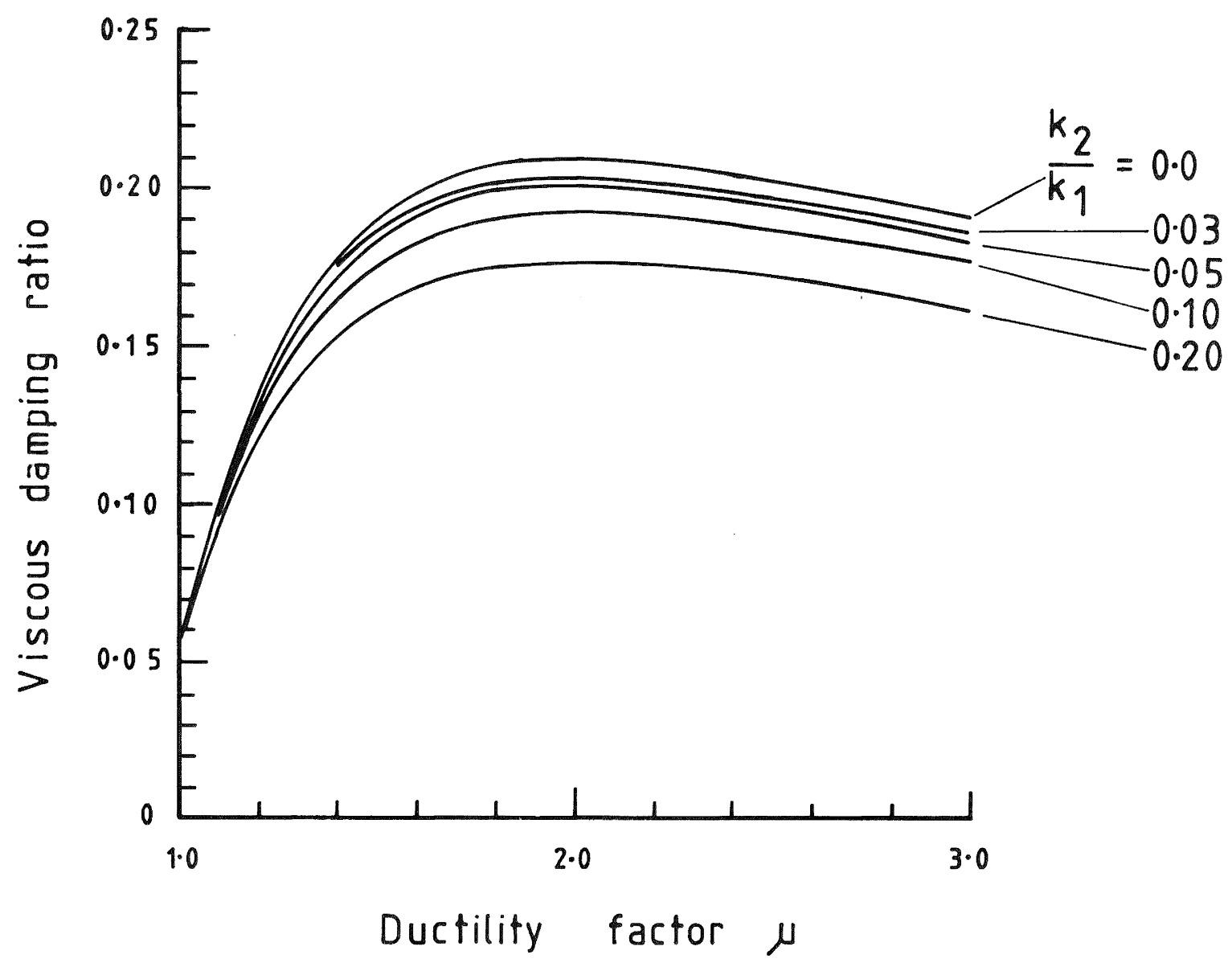

FIG. C 10.1 EQUIVALENT VISCOUS DAMFING FOR BILINEAR HYSTERETIC SYSTEM 
vibrational response of bridges but at the present time insufficient results have been published to enable satisfactory conclusions to be drawn. Inclusion of out of phase inputs adds considerable complexity to a dynamic analysis and thus it is recommended that at present the analysis should be simplified by neglecting this effect.

C10.6.1 For members intended to remain elastic under design earthquake the stiffness should be taken as the mean of the value computed from the curvature in the member at first yield of the tensile reinforcement and the value equivalent to the gross uncracked section of the member. Design aids are available in CDP $810 \mathrm{ClO} .13 / \mathrm{A}$ for determining the stiffness at first yield. For members in which primary plastic hinging is intended to occur, and a time-history inelastic analysis is adopted, the stiffness should be based on the curvature at first yield of the tensile reinforcement. The equivalent stiffness for moderate inelastic behaviour is covered in $\mathrm{Cl0.2.2.}$

C10.6.2 The hysteretic force-displacement relationships recommended for prestressed concreteC10.3, C10.14, reinforced concrete and steel members are expected to be a sufficiently accurate representations for design purposes. The single most important parameter required in an inelastic analysis is the yield level and since this can only be estimated to a moderate degree of precision no increase in accuracy would be obtained by using a more refined force-displacement curve. Under the design earthquake no significant degradation should occur in the forcedisplacement loop of a well detailed plastic hinge or energy absorbing member and thus a non-degrading loop has been recommended.

C10.6.3 In contrast with bridges, buildings have non structural components and more complex lateral load resisting systems that may give rise to higher damping values. Thus in general it is reasonable to assume lower overall damping values for bridges than normally assumed for buildings and at present there appears to be no justification for using overall values higher than the recommended value of $5 \%$.

Soil-structure interaction effects may result in significant additional damping on some bridge sites but at the present time there is no conclusive experimental evidence that would enable specific damping values to be adopted in design. Further research is continuing in this area and eventually it should be possible to make a rational allowance for damping from soil-structure interaction. If an analysis is carried out in which the soil is modelled as an inelastic material then the damping associated with the structural system above the foundation level should be taken as $3 \%$ see section 4.3 .

Wilson and PenzienC10.22 have described a method of setting up a damping matrix to give specified values of damping in each mode. The disadvantage of this method is that it results in a full matrix and greater computational costs. However where the computer program allows the complete matrix to be set and running costs are not significant it is recommended that the Wilson and Penzien method be used to give identical damping in each mode. Where Rayleigh damping is assumed the damping matrix is defined by

$$
\underline{C}=\alpha \underline{M}+\beta \underline{K}
$$

where $\underline{M}=$ the mass matrix

$$
\begin{aligned}
& \underline{K}=\quad \text { the stiffness matrix } \\
& \alpha, \beta= \text { scalar quantities that can } \\
& \text { be evaluated by specifying } \\
& \text { the damping and natural } \\
& \text { frequency of any two modes } 10.6
\end{aligned}
$$

For bridge structures, a satisfactory damping matrix can generally be set up by using the frequencies and damping of the two most dominant modes of vibration 10.6 . The damping specified in section 10.6.3 should be used for the two modal values. This procedure may result in very large damping values being introduced in the higher modes and an alternative approach which reduces this effect is to specify the damping in the first and a relatively high mode, for example the tenth mode. Although higher mode damping values have been found to have a significant influence on the response of building frames $\mathrm{Cl0} .4$ it is unlikely that this would be the case for bridge structures and either of the above methods for setting $\alpha$ and $\beta$ should be satisfactory.

C10.7.1 Since the code design approach is essentially a simplified modal spectral analysis in general this method should produce similar forces and displacements to the code. Differences between the two methods should only occur when there is significant higher mode response.

C10.7.2 It is intended that if the designer elects to carry out a time-history or modal spectral analysis, that full

advantage should be taken of any benefits, such as a reduction in strength, which these more refined methods of analyses may show to be justifiable.

\section{C10.8 REFERENCES:}

Details of programs for dynamic analysis are given in references C10.2, C10.9, Cl0.11, C10.18, C10.20 and C10.21. Buckléclo. 2 gives a comprehensive set of abstracts for bridge programs available in New Zealand.

C10.1 Anagnostopoulos, S.A., Haviland, R.W. and Biggs, J.M., (1978) "Use of Inelastic Spectra in Aseismic Design", Journal of the Structural Division, ASCE, Vol 104, STl, January 1978 . 
C10.2 Buckle, I.G., (1979) "Computer Program Abstracts for Bridge Analysis and Design", Report 217, School of Engineering, University of Auckland, 1979.

Cl0.3 Blakeley, R.W.G., and Park, R., (1973). "Prestressed Concrete Sections with Cyclic Flexure", Journal of the Structural Division, ASCE, Vol 99, ST8, August 1973.

C10.4 Carr A.J., Personal Communication, University of Canterbury, Christchurch.

Cl0.5 Chen, M. and Penzien, J. (1975)

"Analytical Investigations of Seismic Response of Short, Single, or Multiple - Span Highway Bridges", EERC 75-4, University of California, Berkeley, January 1975.

C10.6 Chen, M. and Penzien, J. (1977) "Nonlinear Soil-Structure Interaction of Skew Highway Bridges" EERC 7724 , University of California, Berkeley, August 1977.

C10.7 Iwan, W.D. and Gates N.C. (1979) "Estimating Earthquake Response of Simple Hystertic Structures", Journal Engineering Mechanics Div., ASCE, Vol 105, No EM3, June 1979.

C10.8 Jennings, P.C. (1968) "Equivalent Viscous Damping for Yielding Structures", Journal of the Engineering Mechanics Division, ASCE, Vol 94, No EMl, February, 1968.

Cl0.9 Kanaan, A. and Powell, G.H. (1973) "Drain - 2D General Purpose Computer Program for Inelastic Dynamic Response of Plane Structures," EERC 73-6, University of California, Berkeley, April 1973.

C10.10 Kaul M.K. (1978) "Spectrum Consistent Time - History Generation" "Journal of the Engineering Mechanics Division, ASCE, Vol 104, EM4, August 1978.

Cl0.11 Mondkar, D.P. and Power, G.H. (1975) "ANSR - 1, General Purpose Program for Analysis of Nonlinear Structural Response," EERC 75-37, University of California, Berkeley, 1975.

Cl0.12 Murakami, M. and Penzien, J. (1975) "Nonlinear Response Spectra for Probabilistic Seismic Design and Damage Assessment of Reinforced Concrete Structures," EERC 75-38 University of California, Berkeley, November 1975.

C10.13 N.Z. Ministry of Works and Development, "Ductility of Bridges with Reinforced Concrete Piers", Civil Div., Pub. CDP810/A, April 1975.
C10.19

C10.20

C10.23

C10.14

C10.16

C10.18

C10.21

C10.22

Wu, R.W., Hussian, F.A. and Liu L.K., (1978)"Seismic Response Analysis of Structural system Subjected to Multiple Support Excitation", Nuclear Engineering and Design 47, 1978 .

Park, R., and Blakeley, R.W.G., (1973). "The Response of Prestressed Concrete Structures to Earthquake Motions", New Zealand Engineering, Vol 28, No. 2, February 1973.

Penzien, J. and Watabe,

"Characteristics of 3 Motions", Earthquake Engineering and Structural Dynamics, Vol 3, 1975 .

Porter, F.L. and Powell, G.H. (1971) "Static and Dynamic Analysis of Inelastic Frame Structures", EERC 71 - 3, University of California, Berkeley, June 1971.

Scanlan, R.H. and Sachs, K. (1974) "Earthquake Time Histories and Response Spectra", Journal of the Engineering Mechanics Division, ASCE, Vol 100, No.EM4, August 1974.

Sharpe, R.D. (1974) "The Seismic Response of Inelastic Structures", Report No. 74-13 Department of Civil Engineering, University of Canterbury, November 1974.

Tsai, N.C. (1972) "Spectrum Compatible Motions for Design Purposes", Journal of the Engineering Mechanics Division, ASCE, Vol. 98 , No. EM2, April 1972.

Tseng, W.S., and Penzien, J. (1973) "Linear and Non-linear Seismic Analysis Computer Programs for Long Multiple Span Highway Bridges," EERC 73-20, University of California June 1973. P., Gasparini, D. , and Luyties, W. (1976), "Evaluation of Seismic Safety in Buildings, Report No. 3, Comparison of Seismic Analysis Procedures for Elastic Multi-Degree Systems, Publication No. R76-5, Department of Civil Engineering, MIT, January 1976.

Wilson, E.L., and Penzien, J. (1972) "Evaluation of Orthogonal Damping Matrices" International Journal for Numerical Methods in Engineering, Vol 4, January in En 